Journal of Law \& Social Studies (JLSS)

Volume 2, Issue 2, pp 66-72, 2020

www.advancelrf.org

\title{
Protection of Children Participating in Hostilities under International Humanitarian Law and Human Rights Law: Issues of Compliance by Non-State Actors
}

\author{
Sana Taha Gondal \\ Internee at Supreme Court, Islamabad, Pakistan \\ Advocate High Court \\ Email: sana_taha@live.com
}

\begin{abstract}
Children enjoy legal protection under international humanitarian law and international human rights law. In situations of armed conflict, children are granted not only general protection as civilians, but special protection as children. Several legal provisions exist in the Geneva Conventions and its Additional Protocols, along with the Convention on the Rights of Child and its Second Optional Protocol on Children in Armed Conflicts. However, despite the current legal framework providing protective rights to children, there are serious issues of compliance by non-state actors, particularly in reference to inducting and using child soldiers. This highlights several legal challenges to international humanitarian law vis a vis the diminished protection of children taking direct part in hostilities. This article discusses the current legal regime protecting children in armed conflict, who take direct and indirect part in hostilities. Thereafter, an analysis is made of situations of international and non-international armed conflicts and the difference in protections accorded to these children, respectively. Lastly, an analysis is made of the compliance mechanisms that may be developed for non-state actors under international humanitarian law to prevent recruitment of children for taking direct or indirect part in hostilities. The issues of compliance by non-state actors and possible responses to such challenges are also addressed.
\end{abstract}

Keywords: Children, protection, armed conflict, child soldiers, international humanitarian law, non-state actors

\section{Introduction}

The United Nations (UN) Secretary General's Annual Report of 2017 on children and armed conflict reported that in South Sudan alone, 1022 children were being recruited and used in the year 2016, while in Afghanistan and Yemen, 3512 and 1340 child casualties were recorded respectively. Over 2000 children were reported to be maimed or killed in Iraq and the Syrian Republic. The Report further found that government forces had committed 4000 violations against children and non-state actors (NSAs) had committed 11500 of such violations against children. All these atrocities took place in the context of an armed conflict, attracting a distinct body of law applicable in such situations. The law applicable is the law of armed conflict, also referred to as the law of war, or as the international humanitarian law (IHL). IHL is complemented by the international human rights law (IHRL) in times of an armed conflict.

IHL provides general as well as special protection to children; in the former case, as persons not participating in hostilities in an armed conflict, and in the latter case, as specially protected persons under IHL. However, the increased involvement of children in armed conflict raises the question of the effectiveness of these protections and rehabilitative mechanisms available for said children. For this purpose, it is essential to determine the kind of involvement of children in an armed conflict; the assistance of children may range from indirect help to physically taking up arms and participating in the actual fighting.

This article discusses the protections available to children in situations of armed conflict, if they participate, directly or indirectly, in hostilities. The applicable law is also distinguished in terms of age, i.e. whether the child is below 15 years of age or is between 15 to 18 years of age. Furthermore, a distinction is made between international armed conflicts (IACs) and non-international armed conflicts (NIACs) and the protections afforded to children in both situations respectively. 
Another aspect essential to the protection of children is the issues faced in compliance of IHL by NSAs. This article further highlights these issues of compliance and their reasons as well as explores the need for ensuring better enforcement in this regard.

\section{Protection under IHL}

The law of armed conflict, or IHL, pertains to armed conflicts either of international or non-international character (i.e. IACs or NIACs). IACs exist when there is a conflict between two or more states whereas NIACs exist where a conflict arises between government forces and forces of one or more-armed groups, or a conflict between such armed groups on the territory of a state.

To distinguish between these two kinds of armed conflicts is essential for distinguishing which body of law would apply for protection of children in each situation. The law applicable to IAC is more elaborately codified in the four Geneva Conventions (GCs), the Additional Protocol I (AP I), and The Hague Conventions, along with the non-codified source of customary IHL. The four GCs, with universal ratification, are a part of customary IHL.

To the contrary, in situations of NIAC, only common Article 3 of the GCs applies, along with Additional Protocol II (AP II) (if ratified by the state in question), and customary IHL as applicable to NIACs. Article 4 of the Hague Convention for the Protection of Cultural Property in the Event of Armed Conflict 1954 also applies to NIACs as a minimum standard.

\subsection{Protection Afforded to Children in IACs}

\subsubsection{The Fourth GC on Protection of Civilians}

The fourth GC Relative to the Protection of Civilians Persons in Time of War pertains to protection of the civilian population. Civilians are defined negatively as those persons who are not members of the armed forces or armed groups subject to a responsible command, or who are not part of any militia or voluntary corps that form a part of such armed forces, including members of organized resistance movements, and who are not levee en masse. Children, so long as they do not lose their protection by being involved in any of the aforementioned acts, would enjoy the general protection afforded to civilians under IHL. Merely accompanying armed forces or organized armed groups would not mean that children lose their protection.

Part II of the fourth GC, Articles 13 to 26, pertain to protection of civilian populations. These articles ensure the right of children under 15 years of age, expectant mothers and mothers of those under 7 years of age, to have access to hospitals and safety zones. The convention provides that protected civilians, including children not partaking in hostilities, are to be saved from the consequences and effects of war by providing neutralized zones aimed at sheltering these persons and by prohibiting upon them the performance of any work which is of military character. Even when placed under the control of an Occupying Power, the Occupying Power is prohibited from compelling persons under 18 years of age to work, or to undertake any work which would amount to taking part in military operations.

Other protections for children are also discussed in the convention, including provisions pertaining to permitting free movement of food, clothing and medicines, and for children to be assisted when they are separated from their families or are orphaned. However, for the purpose of this article, the protections, and their lack thereof, for children taking direct or indirect part in hostilities will be discussed.

\subsubsection{Additional Protocol I}

The AP I, as applicable to IACs, provides for protection of children in more detail than the fourth GC. Children must be treated with care and aid, as required, according to the AP I, even if they take direct part in hostilities or attain the status of prisoners of war. The protocol also sets the minimum age of recruitment of children to be 15 years, and further provides that for children above the age of 15 and below the age of 18 recruited in armed forces, they should only be recruited after those older than them have been recruited. Article 77 further provides that children, who commit a crime in the situation of an armed conflict, must be tried separately from adults, and while being detained, unless they are being accommodated in family units. Death penalties are also prohibited for crimes committed by a person when he was below 18 years of age.

\subsection{Protection Afforded to Children in NIACs}

\subsubsection{Common Article 3 of GCs}


The minimum requirement to be followed by any state in a NIAC is that of common Article 3 to the four GCs and customary IHL as applicable to NIACs. Article 3 pertains to protection of persons who are not partaking in hostilities. It is prohibited to inflict violence to the life and person of such civilians, as well as to take them hostages, to commit outrages on their personal dignity and to pass sentences against them without judgments pronounced by duly and regularly constituted courts. It does not specifically grant rights to children, but for persons not partaking in hostilities, the right to be treated humanely is laid down as a bare minimum for states to follow.

\subsubsection{Additional Protocol II}

AP II, as applicable to NIACs, enhances on the basic guarantees provided in common Article 3 to the GCs. However, common Article 3 is applicable to all NIACs, whereas the AP II only applies to NIACs that meet the requirements of a NIAC as laid down in Article I of the same. This means that many of the protections granted in AP II to children would not be applicable to more than 168 states, i.e. those that have ratified the same, as well as several armed conflicts would be precluded from it that do not meet the additional criteria of AP II; i.e. the additional requirement of having 'effective control' of part of territory of a state involved in NIAC.

AP II provides for similar, albeit curtailed, protections for children as enlisted above from AP I in IACs. It provides for certain protections such as ensuring the education of children, for reuniting them with their families if separated, and for their removal from conflict zones in the country. An additional guarantee provided in AP II is that not only does it prohibit recruitment of children below 15 years of age by governments, but also by armed groups opposing the same (i.e. NSAs). As provided for in AP I, children below 15 years of age who directly participate in hostilities do not lose the right to be provided care and aid that they require, to be provided education, and to be reunited with their families. The protocol also provides that if, at the time of commission of a crime, the perpetrator was below 18 years of age they are not to be subjected to death penalty.

\section{IHRL and IHL}

In addition to the abovementioned variations of IHL applicable in NIACs and IACs, IHRL, as applicable in peacetime and in war, is also relevant for a wholesome discussion on the rights of children involved in armed conflicts. While IHRL, which regulates how states treat individuals in their territory, applies in its entirety in peacetime, certain provisions of IHRL may be suspended in emergencies or situations that threat the security of a nation. However, not all human rights may be derogated from in these situations of emergencies and certain non-derogable rights prevail regardless of the circumstances, such as the prohibition of torture and slavery.

It must be understood that IHRL continues to apply in armed conflicts as lex specialis and not as lex generalis, i.e. IHRL acts as complementarily to IHL and reinforces the protections provided for by the latter. The rights of children in armed conflicts, therefore, cannot be fully assessed without a study of both, IHL and IHRL, acting as complementary to one another in an armed conflict.

\subsection{Convention on the Rights of Child}

Along with the Universal Declaration on Human Rights (UDHR) and International Covenant on Civil and Political Rights (ICCPR), the UN Convention on the Rights of Child (CRC) also lays down basic human rights for children. The CRC defines all persons under the age of 18 as children. However, Articles 38 and 39 of CRC deal with children in situations of an armed conflict and provide for adherence to IHL when dealing with the same.

Similar to protections afforded in IHL under the GCs and APs, CRC does allow for those who are between 15 and 18 years of age to be subjected to trainings and lays down that should not be preferred while taking part in hostilities when there are older combatants present. Similarly, those below 15 years of age are not to be made to take direct part in hostilities. Furthermore, if a person has been involved in the commission of a crime before he attained the age of 18 , he may not be awarded death penalty.

Article 39 of the CRC also mandates it upon the state parties to assist children in recovering psychologically and physically in a post-conflict situation and to help them reintegrate in society. All of CRC's provisions apply in situations of an armed conflict as these are non-derogable rights. However, the enforcement of these rights becomes restricted in times of an armed conflict. This is because although the rights of children under CRC are not suspended, the enforcement mechanisms during an armed conflict become weak. The UN Committee on the Rights of Child cannot report in situations of an armed conflict unless the state involved publishes its own report on the matter and the Committee reports based on the same. 


\subsection{Optional Protocol I to Convention on Rights of Child}

The Optional Protocol to CRC on Involvement of children in Armed Conflict (OPCRC) increased the required minimum age for participation of children in hostilities from 15 to 18 years for state forces. Albeit, it only mandated upon states to take feasible measures so as to prevent such participation, which allowed for states to interpret the word 'feasible' in a lenient way and create a weaker obligation for themselves. It also prohibited forced or compulsory recruitment of those under 18 years of age in the armed forces of the state. However, the OPCRC does allow for states to conduct voluntary recruitment of those above 15 years of age, provided that the age has been proved to be above 15 years and the induction is voluntary.

OPCRC also prohibits the use of child soldiers, those under 18 years of age, by non-state armed groups and necessitates for criminalization of such acts. This sets twofold standards for states and NSAs, becoming one of the many factors causing issues in compliance by NSAs. While NSAs are prohibited from recruiting anyone below 18 years of age, states can train those above 15 years of age and below 18 years of age if the process of recruitment is voluntary.

The implementation and monitoring of OPCRC is the responsibility of the Committee on the Rights of Child, although it has been considered to establish a separate committee for OPCRC as the Committee on Rights of Child cannot directly report or monitor in a situation of emergency nor does it have the mandate to hear individual complaints in such situations.

\section{Diminished Protection of Children}

It has been discussed that once children participate in hostilities; they lose their protections to a certain degree under IHL. Those above 15 years of age and below 18 years of age would be classified as combatants if they take up arms. However, those who are below 15 years of age are to be taken care of and provided aid to even if they are captured while directly participating in hostilities. In case of becoming Prisoners of War, the Third GC, Article 16, allows for privileged treatment on the basis of age for these children.

However, during the time that these children partake in hostilities, and are neither captured nor have laid down arms, they lose the protection afforded to them. If captured, then their status is that of civilian internees. It should be noted however; they will not cease to enjoy the protections accorded to them merely for accompanying armed groups or armed forces or for indirectly participating in hostilities, such as cooking or cleaning for them.

\subsection{Conviction for Crimes}

It has already been discussed that children who are perpetrators of crimes when below 18 years of age would not be subjected to death penalty; however, they may still be tried before a court of law and be sentenced otherwise for their actions under IHL. While national courts have their own independent standards, this article will shed light on the standards set by international courts for trial of child soldiers.

The jurisdiction of International Criminal Court (ICC) does not extend to those below 18 years of age at the commission of a crime. However, the International Criminal Tribunal for former Yugoslavia, the International Criminal Tribunal for Rwanda and the Special Court of Sierra Leone do not prohibit the trial of juveniles, yet, the prosecutors of these courts have shown a tendency to focus on trial of persons above 18 years of age.

The CRC also provides, in Article 40, for protection of the right of a child to due process of law in situation of an armed conflict, as well as the preference of rehabilitative measures over retributive measures. Certain international standards are applicable for ensuring the due process of law for children facing criminal charges during or after an armed conflict. IHL itself ensures fundamental guarantees, in both IAC and NIAC, for those who are subjected to criminal trials.

This shows that prosecution of child soldiers is not prohibited by international law, but their reintegration and rehabilitation has been prioritized over their retribution. IHL, as well as the CRC and Paris Principles encourage prohibition of death penalties for crimes committed by those before they were 18 years of age.

\section{Issues of Compliance by Non-state Actors}

NSAs have become an integral part of armed conflicts, especially because of their enhanced roles in NIACs which have become the more common forms of armed conflicts in the contemporary world. As reported in the 2017 Report of the Secretary General, while NSAs were responsible for 11,500 crimes against children. Therefore, compliance by NSAs would impact the protection of children greatly in situations of an armed conflict. 
Common Article 3 of the GC provides protection to NSAs in addition to AP II, which enhances said protection in an armed conflict and gives them certain rights to take up arms and be considered insurgents, instead of criminals, as is the case in peacetime.

IHL, in addition to being binding upon sovereign states, is also binding upon NSAs. A study conducted by ICRC in 2005 showed that almost 140 rules of IHL govern the NSAs, and it is also the opinion of many experts that certain standards of IHRL are also binding upon NSAs. There are certain treaties that create obligations on NSAs, although the language does not seem to imply that they are strictly binding. Article 4(1) of OPCRC is one such example where the word 'should' is used instead of 'shall', where recruitment of child soldiers is being prohibited.

Issues of compliance by NSAs are one of the major challenges facing IHL in the contemporary world. This stems from several issues, including the fact that NSAs are legally bound by treaties to which they did not voluntarily consent, nor were they a part of its formulation. This reduces their willingness to comply with IHL as well as excludes their considerations from the present legal system, making it less comprehensive and effective. Another problem is that the compliance mechanisms are weak in themselves even when it comes to states, but with NSAs an increased challenge is faced because of the fact that many of these enforcement mechanisms are in the hands of the state.

\subsection{Ensuring Compliance through Engagement and Advocacy}

Of the major problems faced in this context is that NSAs are often not aware of the rules of IHL applicable to them. Hence, an important step in ensuring compliance is the dissemination of rules of IHL amongst NSAs. Recruitment of child soldiers, or using children in an armed conflict, is an example of such prohibitions of which NSAs are often unaware. Consequently, they are often also oblivious to the potential individual liabilities of these violations. Marco Sossoli has advocated that a simple code of conduct be prepared and disseminated amongst NSAs for a simple understanding of IHL by armed groups.

Another way is that armed groups be provided advisory services by impartial organizations, e.g. ICRC, to reduce such violations. Furthermore, information regarding IHL should be provided to military commanders instead of political leaders to ensure compliance, and information could also be disseminated to populations at large through the media or internet etc.

\subsection{Ensuring Compliance through Monitoring, Reporting and Verification}

One of the methods of ensuring compliance by NSAs is monitoring, reporting and verification (MRV). The MRV mechanisms often emanate from various treaties or agreements, and one such method is through the regional, and UN treaties and Resolutions. MRV mechanisms may also be developed independent of state involvement, such as the Deed of Commitment under the Geneva Call, an NGO, working to engage NSAs to abide by humanitarian norms. Although the GCs and their APs do not contain reporting mechanisms, there are several UNSC resolutions as well as other IHL and IHRL treaties ensuring MRV in armed conflicts for protection of children.

Several UN Security Council Resolutions have been passed to strengthen the implementation and monitoring and reporting of crimes against children in armed conflicts. The first UNSC resolution, no. 1261, on children affected by armed conflict was adopted under Chapter 6 in 1999.7 resolutions have been adopted by the UNSC on the issue ever since. The resolution addressed, inter alia, the issue of recruitment and use of children in situations of conflicts. The second resolution no. 1314 of 2000 expanded the list of concerns iterated in the UNSC resolution 1261 and called for action pertaining to same. In the Resolution no. 1379 of 2001, the UNSC asked the Secretary General to add a list of parties that recruit children or use them in violation of IHL in his annual report. This list later became famous as the list of shame.

A problem with these MRVs, however, is that they address states and often neglect NSAs. Even when the compliance mechanisms do address NSAs, they are often weak and not applied in practice. Another issue is that NSAs are not a part of the MRV mechanisms based on treaties in practice. To the contrary, MRVs mechanisms that do involve NSAs, and not based on treaties, are either new or have not been comparatively analysed, leaving much room for discovering their practice and impact on NSAs.

Other than MRV, comprehensive active engagement with the NSAs is another mode through with compliance with IHL can be ensured. Steps can be taken to involve NSAs in the decision-making process, such as 'unilateral declarations, special agreements, Memoranda of Understanding, 'Ground Rules', Action Plans, or deeds of commitment.' Organizations already working on engagement with NSAs need to be further supported in their efforts, 
such as the ICRC, Geneva Call, Human Rights Watch, Amnesty International, and the Centre for Humanitarian Dialogue.

\subsection{Ensuring Implementation through Deterrence}

One of the ways in which implementation of IHL may be ensured in protecting children is through accountability of those who commit these crimes. The International Labour Organization (ILO) Convention 182 concerning the Prohibition and Immediate Action for the Elimination of the Worst Forms of Child Labour 1999 also applies to children below 18 years of age and also entailed provisions on child soldiers as a form of child labour. The ILO Recommendation 190 called on member states to make such recruitment practices a criminal offence.

\subsubsection{International Criminal Court}

The 'conscription or enlistment' of children under 15 years of age or using them to actively participate in hostilities in an IAC or NIAC, is dealt with as a war crime under the ICC Statute, Article 8 (2)(b).

One of the most remarkable developments in this area has been the indictment of Thomas Lubanga by the ICC for the recruitment of child soldiers. This has led to deterrence amongst several groups with respect to recruitment of child soldiers, albeit, it still prevails. It is essential to increase accountability of those who continue to recruit child soldiers and commit atrocities against them in an armed conflict for ensuring compliance of the prevailing law. The ICC has also issued many high-profile warrants for arrest for those accused of enlisting children below the age of 15 in armed groups.

\subsubsection{Special Court of Sierra Leone}

The Special Court of Sierra Leone, also has jurisdiction to conduct trial of persons who commit the crime of conscription or enlistment of children in armed forces below 15 years of age, or using them to partake in hostilities along with armed groups. Within 7 years of its establishment, by 2009, the court had 13 indictments, and of these 6 was convicted by the court. The court has also declared that the abovementioned prohibition is a war crime under customary IHL.

\section{Conclusion}

The phenomenon of child soldiers being used in various conflicts is rapidly gaining momentum. Although, it is not novel, the growing rate of violations of IHL against children in armed conflicts by both state forces and NSAs is alarming. Records show, however, that issues of compliance are far greater in NSAs than by states when it comes to children in armed conflicts. IHL provides for several protections for children when they are not participating in hostilities, such as education, right to be kept with their family, right to be taken to safety zones etc. However, these protections are also significantly diminished when children take up arms and start participating in hostilities. During combat children lose the protections they have under IHL. Although, the protections are restored to some extent when they are captured or fall into the hands of the opposite party.

The problems then, arise in terms of compliance with the existing IHL. There are several means to achieve this, for example, by ensuring compliance by engaging NSAs and advocating IHL amongst the same. Another way is through deterrence and prosecuting those who induct and recruit child soldiers. One effective way is by strengthening and improving the MRV mechanisms in place, particularly in context of NSAs and child soldiers.

\section{References}

Covenant on Civil and Political Rights 1989.

“Customary IHL Rules” ICRC.

Elimination of the Worst Forms of Child Labour 1999.

Geneva Conventions of 1949.

Geneva Convention I, 1949.

Geneva Convention II, 1949.

Geneva Convention III, 1949. 
Geneva Convention IV, 1949.

Geneva Protocol I, 1977.

Geneva Protocol II, 1977

Hague Convention for the Protection of Cultural Property in the Event of Armed Conflict 1954.

"How is the term armed conflict defined in International Humanitarian Law?," ICRC.

IHL and Human Rights Law

International Bureau for Children's Rights.

"Legal Protection of Children in Armed Conflict," ICRC.

Morgan Kelley, "Challenges to Compliance with International Humanitarian Law in the

Context of Contemporary Warfare," Independent Study Project, no. 1618 (Spring 2013).

Prosecutor v. Alex Tamba and others

Prosecutor v. Charles Ghankay Taylor

Prosecutor v. Joseph Kony and others

Prosecutor v. Sam Hinga Norman.

Prosecutor v. Thomas Lubanga Dyilo.

Protocol to the Convention on the Rights of the Child on the involvement of children in armed conflict 2000.

Statute of the International Criminal Court.

Statute of Sierra Leone.

Statute of Special Court of Sierra Leone.

The Paris Principles (2007).

UN Convention on the Rights of the Child, 1989.

UN Guidelines for the Prevention of Juvenile Delinquency (Riyadh Guidelines) 1990.

UN Rules for the Protection of Juveniles Deprived of their Liberty (Havana Rules) 1990.

UN Standard Minimum Rules for the Administration of Juvenile Justice (Beijing Rules) 1985.

Veuthey, Michel, "Implementing International Humanitarian Law: Old and New Ways" in

Human Rights Protection in the Field, ed. Ramcharan, Bertrand G. (Leiden/Boston: Martinus Nijhoff, 2006).

Vienna Guidelines, 1997.

United Nations Security Council resolution 1261 (1999).

United Nations Security Council resolution 1314 (2000).

United Nations Security Council resolution 1379 (2001).

"United Nations Secretary General's Annual Report on Children and Armed Conflict" (A/72/361) 2017," UNDOCS. 